\title{
Preface (ISIAME 2008)
}

\author{
E. Kuzmann • K. Lázár
}

Published online: 1 April 2009

(C) Springer Science + Business Media B.V. 2009

The International Symposium on the Industrial Applications of the Mössbauer Effect (ISIAME 2008) was held from Sunday 17th to Friday 22th August 2008 at the Eötvös Loránd University in Budapest, Hungary and provided successful and attractive scientific and social programs. The ISIAME 2008 conference was the seventh in the series occurring every 4 years, and followed the scientific mission of those held previously in Hawaii (1984), Parma (1988), Seta (1992), Johannesburg (1996), Virginia Beach (2000) and Madrid (2004), focused on topics that have the potential to attract researchers towards the industrial applications of Mössbauer spectroscopy and stimulated contacts between the industrial and academic worlds.

The conference was attended by 165 participants from 36 countries. The scientific program of ISIAME 2008 conference involved 20 invited lectures, 39 oral and 116 poster presentations.

The contributions were classified according to their content into ten topics:

T1. Nanotechnology

T2. Metallurgy

T3. Biotechnology and pharmaceutical industry

T4. Applied mineralogy

T5. Energy production industry (coal, oil, nuclear, solar)

E. Kuzmann $(\bowtie)$

Eötvös Loránd University, Budapest, Hungary

e-mail: kuzmann@ludens.elte.hu

E. Kuzmann

Chemical Research Center, Hungarian Academy of Sciences,

Budapest, Hungary

K. Lázár

Institute of Isotopes, Hungarian Academy of Sciences,

Budapest, Hungary

e-mail: lazar@iki.kfki.hu 
T6. Electronic and magnetic devices technology, composite and amorphous materials, computer industry

T7. Coatings, interfaces, thin films, multilayers, surface modification, ion implantation technology

T8. Catalysis, electrochemistry, batteries

T9. Corrosion, tribology, environmental friend technology

T10. New methods, methodology

The conference provided a pertinent occasion to commemorate the 50th anniversary of the birth of the Mössbauer method, namely that 50 years ago Professor Rudolf L. Mössbauer published his paper in Zeitschrift für Physik which initialized a new research area, impacting many segments of science and led also to the formation of the Mössbauer community. A session was dedicated in memoriam to Professor Ulrich Gonser and Professor Francisco Eiichi Fujita, who gave outstanding contributions to the industrial applications of Mössbauer spectroscopy, and both excellent scientists passed away at the end of 2007.

IBAME and ISIAME Board meetings were also held during the conference.

The proceedings contain 76 submitted contributions that have been accepted for publication by the reviewers. In the first part of the book the communications of the invited speakers are presented. They are followed by the contributions arranged in correspondence with the ten specified topics. From these reports a broad overview emerges on the most recent results which are attained by applying and developing the Mössbauer method.

The conference was organised by the Eötvös Loránd University, the Institute of Isotopes and the Hungarian Chemical Society. The organizers are thankful for the supports from Eötvös Loránd University, Institute of Isotopes, Hungarian Academy of Sciences, Hungarian Chemical Society, National Office for Research and Technology, Hungary, RITVERC GmbH, St. Petersburg, Handelsvertreter Cyclotron Instruments, Mainz, Mössbauer Effect Data Centre, Asheville, Research Institute of Physics, Southern Federal University, Rostov-on-Don, Tokai Industry Corporation, Chofugaoka City and Wissenschaftliche Elektronik GmbH, Starnberg.

We wish to thank the members of the International Advisory Board and Program Committee for their useful suggestions and comments, and the reviewers of the manuscripts who referred the papers in short time, and all those participants who submitted their contributions to the proceedings.

E. Kuzmann

K. Lázár

(Editors) 